\title{
Report on a child with stricture following foreign body of long duration in the bronchus. Discussion on the management of bronchial foreign bodies
}

\author{
D. T. THOMPSON \\ F.R.C.S. \\ Harari Central Hospital, Southerton, Salisbury, Rhodesia
}

\begin{abstract}
Summary
A case report and the management of a 10-year-old girl who had inhaled a foreign body into the right intermediate bronchus at some unknown (but certainly not recent) time previously is given. A stricture at the site of the impaction of the foreign body was found. The excision of the stricture and repair of the bronchus with pericardium is described together with a 3year follow-up report. The diagnosis and immediate management of foreign bodies in the bronchus are discussed and the importance of differentiating organic and non-organic foreign bodies is stressed. The management of bronchial strictures is discussed as is the result obtained in the above reported case.
\end{abstract}

\section{Introduction}

Case report

A 10 year-old girl, was admitted to hospital with the history of a cough of approximately 3 weeks' duration. On examination the only abnormality noted was absent air entry on the right lower chest posteriorly, associated with dullness to percussion. A dense opacity in the right midzone was shown on $\mathrm{X}$-ray together with radiological features of a middle and lower lobe collapse (Fig. 1). A lateral X-ray showed the shadow to be in the line of the right main bronchus. The patient could not recall any occasion when she might have inhaled any object.

At bronchoscopy the percussion cap of a bullet was removed with some difficulty, it being impacted just distal to the origin of the upper lobe bronchus. The bronchial wall was oedematous at the site of impaction but the lumen appeared to be adequate.

The middle and lower lobes did not inflate in spite of intensive physiotherapy and after a fortnight of this treatment it was decided that the failure to re-expand was probably due to a fibrinous layer on the collapsed lobes.

\section{Materials and methods}

A right thoracotomy 3 weeks after admission showed a thin layer of fibrinous material and this was removed easily. Positive pressure ventilation $\frac{3}{3}$. expanded the lobes to about $75 \%$ of maximal or capacity.

Continuous suction to pleural cavity during the immediate postoperative period kept the lobes $\mathbb{\infty}_{\infty}^{\circ}$ inflated for the first $24 \mathrm{hr}$ but thereafter they col-? lapsed again. Active physiotherapy did not achieve expansion.

A second bronchoscopy carried out one week $\mathbb{D}$ later showed bronchial narrowing at the impaction $\Phi$ site. This was dilated to $9 \mathrm{E}$ and inflation of the lobe was achieved, there being good air entry on auscub $\frac{\Phi}{-}$ tation. As the expansion was not maintained the $\overrightarrow{0}$ child was submitted to a second thoracotom cै approximately one month after admission. The middle and lower lobes were collapsed. The right main bronchus was mobilised and a stenosis identified distal to the origin of the upper lobe bronchus.

The posterior soft tissue portion of the bronchus $\frac{\otimes}{D}$ was incised longitudinally at the site of the stenosis $\cong$ and the narrowing was seen to be confined to this $\overrightarrow{\overrightarrow{0}}$ non-cartilaginous portion. An oval segment of the 3 fibrosed posterior wall was excised leaving a deficit of $2.5 \times 1.5 \mathrm{~cm}$.

A portion of pericardium of approximate size was $\frac{\overline{0}}{3}$ fashioned and the defect closed without tension, interrupted cat-gut sutures being used. The lobes 3 . expanded well with inflation by the anaesthetist.

The patient's postoperative course was uncompli- 응 cated, the lobes taking 3 days to reach full expansion and thereafter remained expanded. She was dis- 궁 charged 3 weeks after operation.

\section{Follow-up}

The patient was kept under review for 3 years. A bronchogram done early in this period showed a $\mathrm{W}$ normal lumen (Fig. 2). She was re-admitted to hospital for bronchoscopy and chest X-ray 30 months after operation. At bronchoscopy it was impossible $\stackrel{\overparen{D}}{\stackrel{D}{\oplus}}$ to identify the site of the patch and the X-ray showed a fully expanded and normal right lung (Fig. 3). 


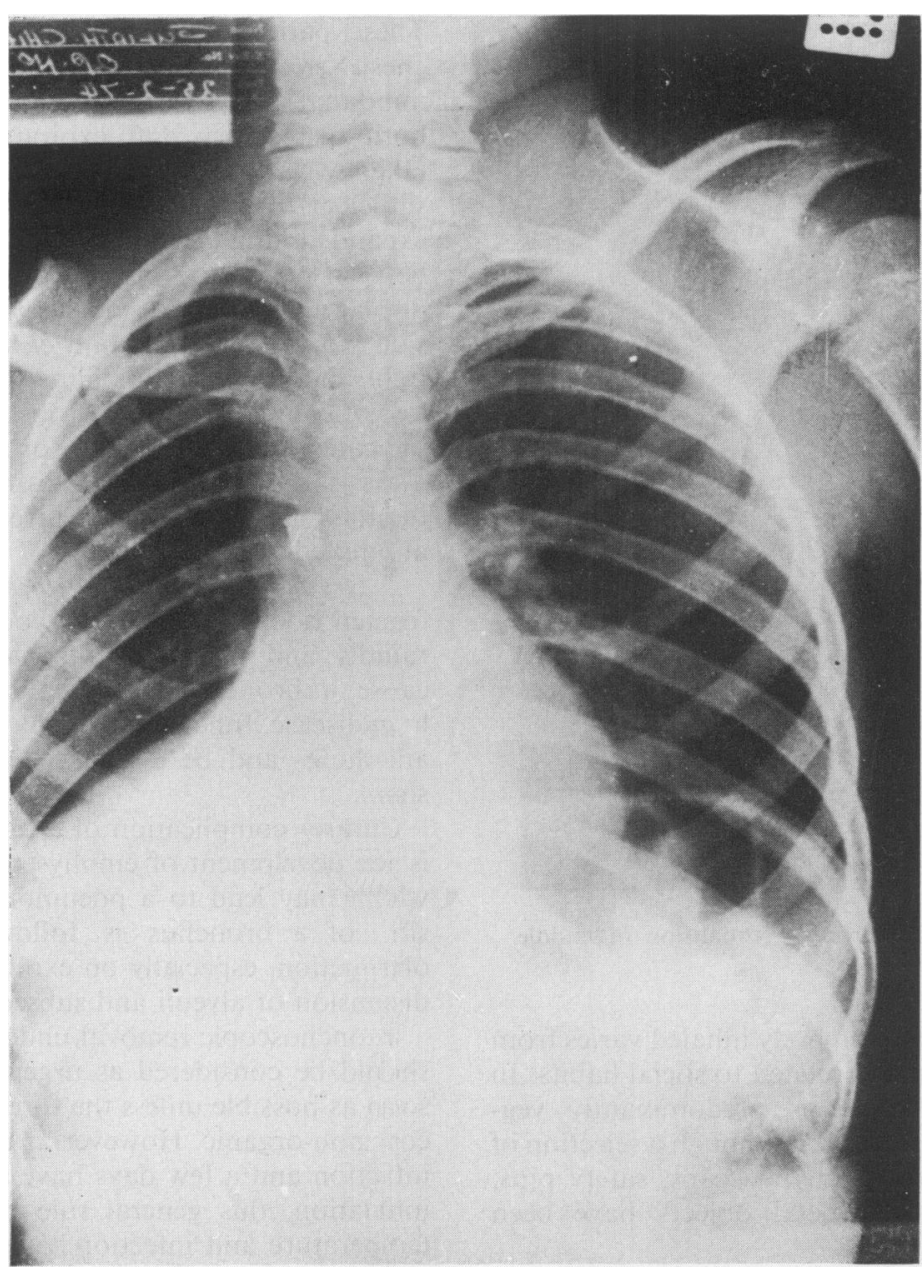

FIG. 1. Foreign body in bronchus with right middle and lower lobe collapse.

\section{Foreign bodies in the bronchial tree}

Foreign bodies in the bronchial tree are often overlooked in the casualty department, especially in young children. The National Safety Council U.S.A. reports (Majd, Mofenson, and Greensher, 1977) that approximately 3000 deaths occur annually in the U.S.A. from inhalation or ingestion of foreign bodies and almost $90 \%$ of these deaths can be attributed to carelessness.

The difficulty arises because children are poor witnesses and they present with a wide variety of complaints which include wheezing, coughing, shortness of breath, features of a respiratory tract infection, aphasia and dysphasia. Unless the inhalation is actually witnessed the smaller child may not recall any untoward episode.

In many cases, by the time the child is brought to hospital coughing has subsided and mistakenly it might be assumed that a foreign body is not present. It must be emphasized that the absence of a cough does not exclude a foreign body - tolerance by the bronchial mucosa appears to develop rapidly, provided the body does not move within the bronchial lumen. With children, a high level of suspicion must be maintained.

\section{Clinical features and diagnosis}

A foreign body in the bronchial tree is rare before the stage of crawling. A review of the literature(Banks and Potsic, 1977; Hussain, 1976; Kim et al., 1973; Law and Kosloski, 1976; Majd et al., 1977; Mearns and England, 1975; Pyman, 1971 ; Weston, 1965) confirmed by a study of the records of the Harari Central Hospital, Salisbury, Rhodesia, shows that there is a fairly even distribution of patients between the ages of one and 6 years, $75 \%$ of whom are male. 


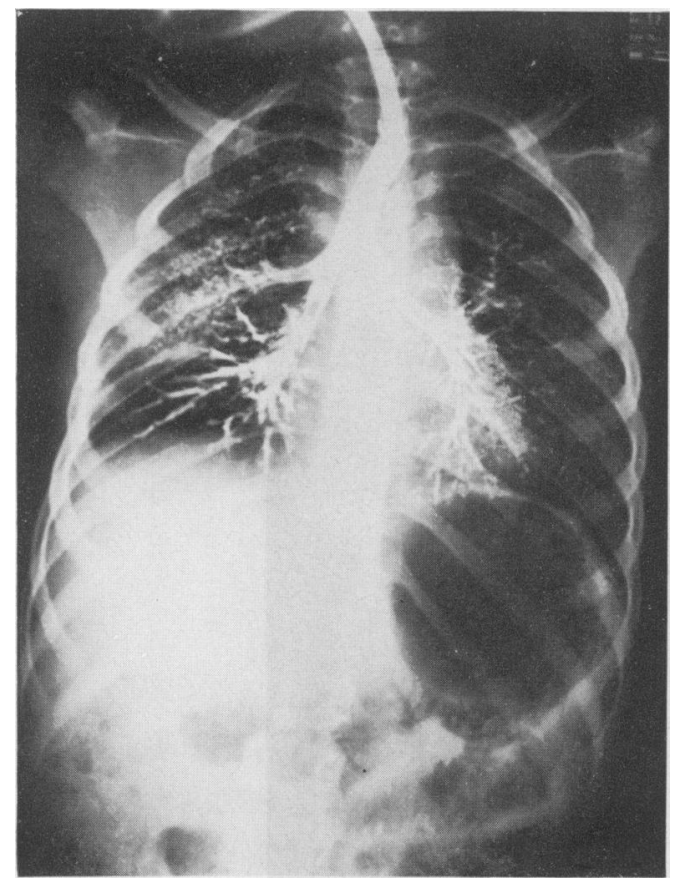

FIG. 2. Bronchogram showing re-expansion of middle and lower lobes.

The nature of the foreign body inhaled varies from country to country and is related to social habits. In Rhodesia, inhaled matter is predominantly vegetable, especially maize seeds, although a selection of other objects, e.g. ball-point pen caps, safety pins, nails, coins, and other metal objects have been removed.

The classically reported triad of features, namely cough, wheezing ventilation and reduced air entry are not a common finding and seem related to the mobility of the object within the bronchial tree. If present, this triad should alert the doctor to the possible presence of a foreign body. As the episode of inhalation and coughing, however, is often forgotten (a common experience in this hospital) the presenting features then become those of a chest infection.

With the present patient it seems likely that the foreign body became impacted fairly rapidly and tolerance established. The whole episode was forgotten until a bout of coughing (probably due to movement) called forth parental and later medical attention.

\section{Management \\ Immediate \\ If a foreign body is suspected immediate steps to support the diagnosis must be taken.}

These patients should always be admitted and a chest X-ray taken at the earliest moment. Bearing in mind that many foreign bodies are not radio-opaque both inspiratory and expiratory films should be taken when possible. With a foreign body of sizes sufficient to impact in a major bronchus, an overo expanded lung or lobe distal to the obstruction mayo be seen on expiration and often is associated with displacement of the mediastinum to the opposite side. Some workers (Majd et al., 1977) recommeno right and left decubitus films-the side which shows? loss of compressibility (i.e. obstructive 'emphysema') $\vec{p}$ indicates the presence of a foreign body.

As soon as clinical assessment of the patient permits, removal of the foreign body should b\&্ট attempted.

i. Organic and dissolving foreign bodies. Vegetablè foreign bodies, especially if cooked, break up fairly $y_{5}^{\prime}$ rapidly and the fragments pass distally and maye cause a bronchopneumonia or other suppurativeo lung disease. Inhaled grass may pass through bronchळ and lungs and be discharged externally through a sinus.

A rarer complication of a bronchial foreign body is the develpment of emphysema (Kim et al., 1973)? which may lead to a pneumothorax. Partial occlu- $\frac{\mathbb{}}{3}$ sion of a bronchus is followed by distal lukg obstruction, especially on expiration - there is over-distension of alveoli and subsequent rupture.

Bronchoscopic removal under general anaesthe should be considered as urgent and carried out $\bar{a}$ as soon as possible unless the foreign body is undoubt edly non-organic. However, if there is obvious ches? infection and a few days have already elapsed since् inhalation, this general rule may be waived unti这 temperature and infection have been brought under $\vec{\rightarrow}$ control with antibiotics. Postural drainage has been recommended by some workers (Law and Koslowski, 1976).

The clinical decision lies between allowing furthe deterioration if the foreign body is left, and aggra- 3 vating pulmonary infection if bronchoscopy is carried out too soon. Oedema develops rapidly at the site of impaction, especially with dissolving foreign bodies (Mearns and England, 1975) and if untreatedB may lead to distal infection, stricture formation, oro both. At bronchoscopy, especially with children, it is? important to keep a check on the cardiac rate? Bradycardia and sometimes cardiac arrest may be caused, particularly if bronchoscopy is carried on too a point where serious oxygen desaturation has de- $N$ veloped. Frequent ventilations of the lungs during bronchoscopy are strongly advised.

ii. Non-organic foreign bodies. If the foreign body is known to be non-organic and the patient is not distressed then removal need not be viewed as urgent? but should be done as soon as possible. An initialo 


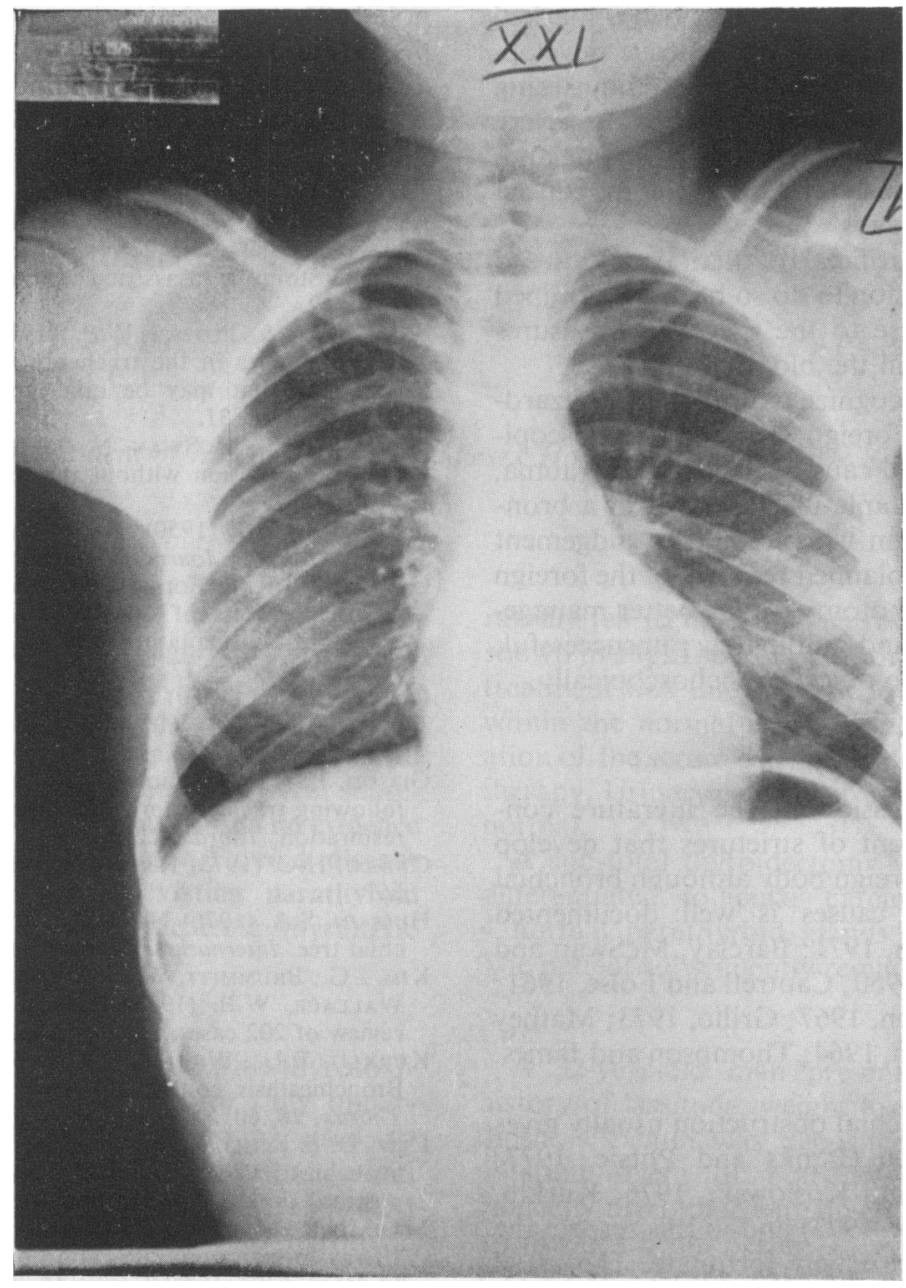

FIG. 3. Normal chest X-ray $2 \cdot 5$ years after operation.

period of $24 \mathrm{hr}$ of inhalational and postural drainage therapy before bronchoscopy is often beneficial.

Impacted non-organic foreign bodies may lead, as in the present patient, to collapse of the obstructed lung without infection supervening, but a stricture usually develops. Infection of course may occur but is less likely than with organic bodies.

The longer term complications of distal infection such as lung abscess, bronchiectasis and empyema have been well documented and will not be discussed, but the immediate post-bronchoscopy care and the management of the rarer bronchial stricture will be considered.

\section{After bronchoscopy}

(a) In most cases even with organic foreign bodies if removal is practised within $24-48 \mathrm{hr}$ of inhalation, there are no further problems. However, if removal has been difficult and prolonged, antibiotics should be given for a few days after the bronchoscopy.

(b) A close watch for cord oedema, stridor, and dyspnoea must be maintained. The pulse and ventilatory rate should be charted half-hourly, certainly for the first $12 \mathrm{hr}$, after a difficult bronchoscopy.

(c) If stridor does develop, then high humidity nursing, according to facilities available, should be started; rapidly developing stridor may necessitate intubation. A tracheostomy is indicated, though rarely, if intubation cannot be tolerated. Usually oedema of the cords subsides within $48-72 \mathrm{hr}$ and progress is uneventful thereafter.

(d) If bronchial tree infection does develop, and 
especially if the foreign body is dissolving, marked inflammation and oedema of the mucosa develop. In these cases, treatment consists of administering oxygen, antibiotics and postural drainage. In severe cases, $4 \mathrm{mg}$ betamethasone (Mearns and England, 1975 ) is given intravenously, and thereafter in reduced doses over the next 3 days.

(e) Intubation and artificial ventilation may have to be practised - the decision to do so being determined by the clinical response to the preceding measures and the changes seen in the blood gas picture.

It is important to recognize that it may be hazardous to remove some foreign bodies bronchoscopically or to do so would cause considerable trauma, for example a metal staple upside down in a bronchus. This is a situation which requires judgement - a thoracotomy with planned removal of the foreign body through a bronchotomy can be better management than many, and ultimately unsuccessful, attempts to remove the object bronchoscopically.

\section{Long-term}

There is little discussion in the literature concerning the management of strictures that develop after inhalation of a foreign body although bronchial stricture from other causes is well documented (Andrews and Pearson, 1971; Barclay, McSwan and Welsh, 1957; Belsey, 1950; Cautrell and Folse, 1961; Gebauer, 1950; Gibson, 1967; Grillo, 1973; Mathey et al., 1971; Thompson, 1964; Thompson and James, 1976)

Long-standing bronchial obstruction usually gives rise to distal infection (Banks and Potsic, 1977; Hussain, 1976; Law and Koslowski, 1976; Kurklu, Williams and Le Roux, 1973) and in this respect the present patient was extremely fortunate. The usual surgical procedure for bronchial stricture is resection with end-to-end anastomosis, although dermal grafts and artificial prostheses have used been with limited success.

In this patient it was decided not to resect the stricture because the bronchial orifices of all three lobes would have been involved in a difficult anastomosis, and the lumen of the middle lobe tronchus might well have been compromised. It was thought too that if the pericardial patch itself in time caused a stricture resection and anastomosis (Naef, 1969; Pauslon and Shaw, 1966; Thompson, 1964; Thompson and James, 1976) would be a more controlled procedure when the patient was older and the bronchial tree larger. As it has transpired these fears were groundless.

It is worthy of note that at the bronchoscopy 30 months after operation, no abnormality could be noted. The speculation is expressed that either the pericardium becomes epithelialized or it contracts down to a thin scar with compensatory growth of the remaining parts of the bronchial lumen.

\section{References}

ANDrews, M.J. \& Pearson, F.G. (1971) Incidence and $\frac{\bar{\sigma}}{\sigma}$ pathogenesis of tracheal stricture following cuffed tube $\overline{\bar{\omega}}$ tracheostomy with assisted ventilation. Annals of Surgery, $\vec{\nabla}$ 173, 249.

Banks, W. \& Potsic, W.P. (1977) Elusive unsuspected foreign bodies in the tracheobronchial tree. A nidus for $\mathrm{S}$ infections that may be quiet for a long time. Clinical $\overrightarrow{0}$ Pediatrics, 16, 31.

BarClay, R.S., McSwan, N. \& Welsh, T.M. (1957) Tracheal reconstruction without the use of grafts. Thorax, 12, 177.

BELSEY, R.H.R. (1950) Reconstruction of intra-thoracic trachea. British Journal of Surgery, 38, 200.

CAUTREll, J.R. \& Folse, J.R. (1961) The repair of circum- if ferential defects of the trachea by direct anastomosis: experimental evaluation. Journal of Thoracic and Cardio- of vascular Surgery, 12, 589.

Gebauer, P.W. (1950) Plastic reconstruction of tuberculous bronchostenosis with dermal grafts. Journal of Thoracic Surgery, 20, 349.

GiBson, P. (1967) Aetiology and repair of tracheal stenosis following tracheostomy and intermittent positive pressure respiration. Thorax, 22, 1.

GrILLO, H.C. (1973) Reconstruction of trachea. Thorax, 28, 667.

HussaIN, S.A. (1976) Neglected foreign body in right bron chial tree. International Surgery, 61, 366.

Kim, I.G., Brummitr, W.M., Humphry, A., Siomra, S.W. WALlACE, W.B. (1973) Foreign body in the airway; review of 202 cases. Laryngoscope, 83, 347.

Kurklu, E.U., Williams, M.A. \& Le Roux, B.T. (197 Bronchiectasis consequent upon foreign body retention. Thorax, 28, 601.

LAw, D. \& Kosloski, A.M. (1976) Management of tracheobronchial foreign bodies in children: a re-evaluation of postural drainage and bronchoscopy. Pediatrics, 58, 363.

MAJd, N.S., Mofenson, H.C. \& Greensher, J. (1977) Lower airway foreign body aspiration in children: an analysis of 13 cases. Clinical Pediatrics, 16, 13.

Mathey, J., Lemoine, J.M., Renault, P. \& Oustrières, G. כ (1951) Reconstruction plastique de la bronche pour sténose tuberculeuse (opération de Gebauer). Revue de la tuberculose et de pneumologie, 15, 68.

Mearns, A.J. \& ENGland, R.M. (1975). Dissolving foreign bodies in trachea and bronchus. Thorax, 30, 461 .

NAEF, A.P. (1969) Extensive tracheal resection and tracheo- 3 bronchial reconstruction. Annals of Thoracic Surgery, 8, 391.

Paulson, D.L. \& SHAW, R.R. (1966) Results of bronchoplastic procedures for bronchogenic carcinoma. Annals 윽 of Surgery, 157, 729.

Pyman, C. (1971) Inhaled foreign bodies in childhood. A review of 230 cases. Medical Journal of Australia, 1, 62.

Thompson, D.T. (1964) A technique for bronchial anasto- $N$ mosis after resection of a position of bronchus. Thorax, 19, $\Omega$ 347.

Thompson, D.T. \& JAMES, M.F.M. (1976) Surgical manage- NN ment of tracheal stricture following positive pressure $\omega$ ventilation. Central African Journal of Medicine, 22, 241. ㅇ

WESTON, J.T. (1965) Airway foreign body fatalities in children. 0 Annals of Otology, Rhinology and Laryngology, 74, 1144. 